\title{
Anatomical Study of the Caudate Lobe with Special Reference to Portal Venous and Biliary Branches Using Corrosion Liver Casts and Clinical Application
}

\author{
Masamitsu Kumon \\ The First Department of Surgery, Kochi Medical School, Kochi, Japan
}

\section{Keywords}

Corrosion liver casts · Liver segments · Anatomy of the liver · Liver surgery · Biliary surgery

\begin{abstract}
The definition and extent of the human caudate lobe in the liver is unclear, and thus, the anatomy of the caudate lobe was studied using 23 corrosion liver casts, with special reference to the portal venous and biliary branches. These branches and their ramification type in the caudate lobe showed that this lobe includes: (1) the Spiegel lobe; (2) the paracaval portion; and (3) the caudate process portion. The three portions often have their own independent branches; for example, the portal venous and biliary branches of the Spiegel lobe were ramified mainly from the left-side tract, whereas those of the caudate process portion were ramified from the right-side tract. The portal venous branches of the paracaval portion were ramified mainly from the left portal vein, while the biliary branches of this portion drained into the right and left biliary tracts at almost equal frequencies. In most cases, the peripheral branches reached the liver surface beneath the diaphragm. Thus, the present division of the caudate lobe into three portions could make the extent of the caudate lobe clear and is considered logical from a clinical viewpoint.




\section{Liver Cancer}

\section{Introduction}

With recent progress in hepatobiliary surgery, the importance of the caudate lobe in the human liver has been increasingly recognized, and anatomical peculiarities of the caudate lobe and procedures used for caudate resection have been reported [1-3]. Topographical nomenclature used for hepatic segments in the United States was proposed by Healey and Schroy [4], while nomenclature used in Europe was proposed by Couinaud [5]. In Japan, Couinaud's liver segmentation was introduced by Hasegawa, and this nomenclature is widely used in the field of liver surgery. However, investigators disagree on the extent and borders of the caudate lobe because Couinaud has not clearly defined the boundary of the caudate lobe.

Thus, we investigated the definition, extent, and clinical significance of the caudate lobe in the human liver using corrosion liver casts. The significance of the caudate lobe in radical liver surgery for a hilar malignancy has also been explored in this study from the standpoint of its clinical application.

\section{Methods and Subjects}

Corrosion liver casts were prepared by injecting colored silicone rubber into the portal vein (blue), hepatic artery (red), bile duct (yellow), and hepatic vein (black) of autopsied livers, followed by removal of the hepatic parenchyma. Detailed accounts of the procedure have been given elsewhere by the present author $[6,7]$.

The casting injection material used in the present series $(n=23)$ was silicone rubber $(n=15)$, polyester resin $(n=5)$, and acrylic resin $(n=3)$. Particular caution was exercised to ensure the accuracy of the procedure, especially when observing the caudate lobe branches above the inferior vena cava. To be more accurate, the peripheral branches were severed and removed as needed to enable observation of the branches from the diaphragmatic or cephalad side, because the branches around the inferior vena cava may not be adequately observed from the liver surface. This made it feasible to directly and macroscopically observe the courses of the primary right and left ramifications of the portal vein from multiple directions, thereby limiting the possibility of errors (Fig. 1, 2).

\section{Results}

In the present 23-case series, the primary ramification of the portal vein was a bifurcation type in 17 of the livers studied (73.9\%), a trifurcation type in 2 of the livers studied (8.7\%), and a right posterior-independent branch type in 4 of the livers studied (17.4\%). The right posterior-independent branch type was described by Kinoshita et al. [8]. Unlike the usual branch types, in the right posterior-independent branch type, the right posterior portal branch directly branches out from the main trunk, and the caudate portal branch frequently branches out from the right posterior portal branch.

There were usually 5 (47.9\%; range $3-6$ ) portal venous branches in the caudate lobe, and there was a mean of 4.35 caudate portal venous branches. There was a mean of 3.8 biliary branches in the caudate lobe (range, 2-6), with 3 biliary branches in $39.1 \%$ of the livers studied and 4 biliary branches in $34.6 \%$ of the livers studied (Table 1 ).

The caudate lobe is generally and incorrectly thought to be composed of the caudate process and the portion protruding toward the left of the inferior vena cava (i.e., the Spiegel lobe). However, the present study showed that there is an important caudate portal branch on the ventral side of the hepatic inferior vena cava. To clarify the definition and extent of the caudate lobe, the present study partitioned the caudate lobe as follows: (1) Spiegel lobe; (2) 


\section{Liver Cancer}

Fig. 1. Biliary branches of the caudate lobe viewed from the ventral side. The arrows indicate 3 biliary ducts in the caudate lobe after separating peripheral venous branches which originate along the left side of the middle hepatic vein (MHV).

Fig. 2. Peripheral branches of the paracaval portion viewed from the cranial side. The arrows indicate peripheral portal branches of the paracaval portion and $\mathrm{L}, \mathrm{M}$, and $\mathrm{R}$ indicate the left, middle, and right hepatic vein, respectively.

Table 1. Number of branches of the caudate lobe

\begin{tabular}{l|l}
\hline Liver Cancer 2017;6:161-170 \\
\hline DOI: 10.1159/000454682 & $\begin{array}{l}\text { @ 2016 S. Karger AG, Basel } \\
\text { www.karger.com/lic }\end{array}$ \\
\hline
\end{tabular}

Kumon: Anatomical Study of the Caudate Lobe with Special Reference to Portal Venous and Biliary Branches Using Corrosion Liver Casts and Clinical Application
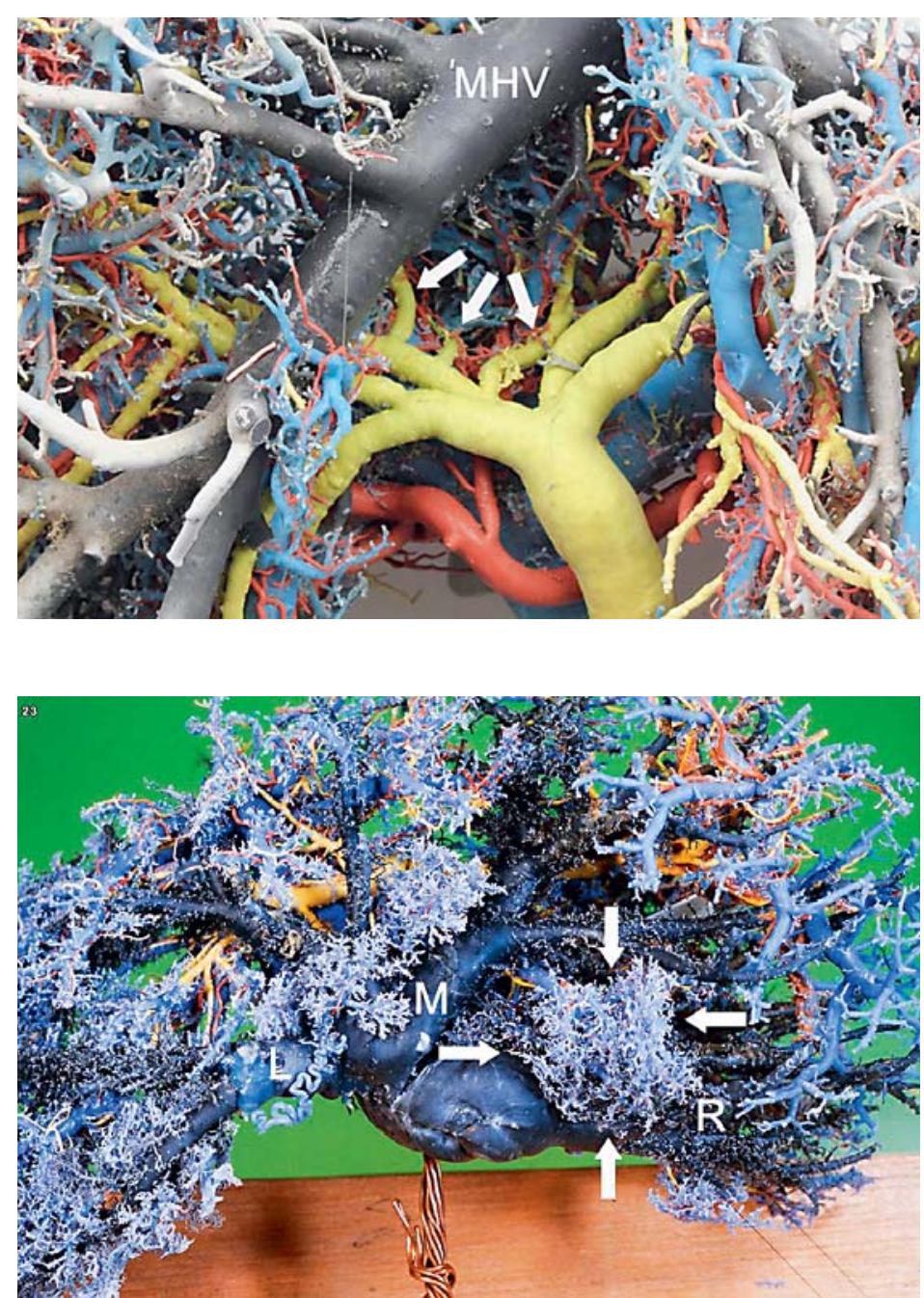

\begin{tabular}{lcc}
\hline Number of branches & Cases & $\%$ \\
\hline Portal vein & & \\
3 & 3 & 13.0 \\
4 & 6 & 26.1 \\
5 & 11 & 47.9 \\
6 & 3 & 13.0 \\
\hline Total & 23 & 100 \\
\hline Biliary duct & & \\
2 & 1 & 4.3 \\
3 & 9 & 39.1 \\
4 & 8 & 34.9 \\
5 & 2 & 8.7 \\
6 & 2 & 8.7 \\
Unclear & 1 & 4.3 \\
Total & 23 & 100 \\
\hline
\end{tabular}


Fig. 3. Portal venous branches in the caudate lobe. 1: Spiegel lobe branch; 2: paracaval branch; 3: caudate process branch.

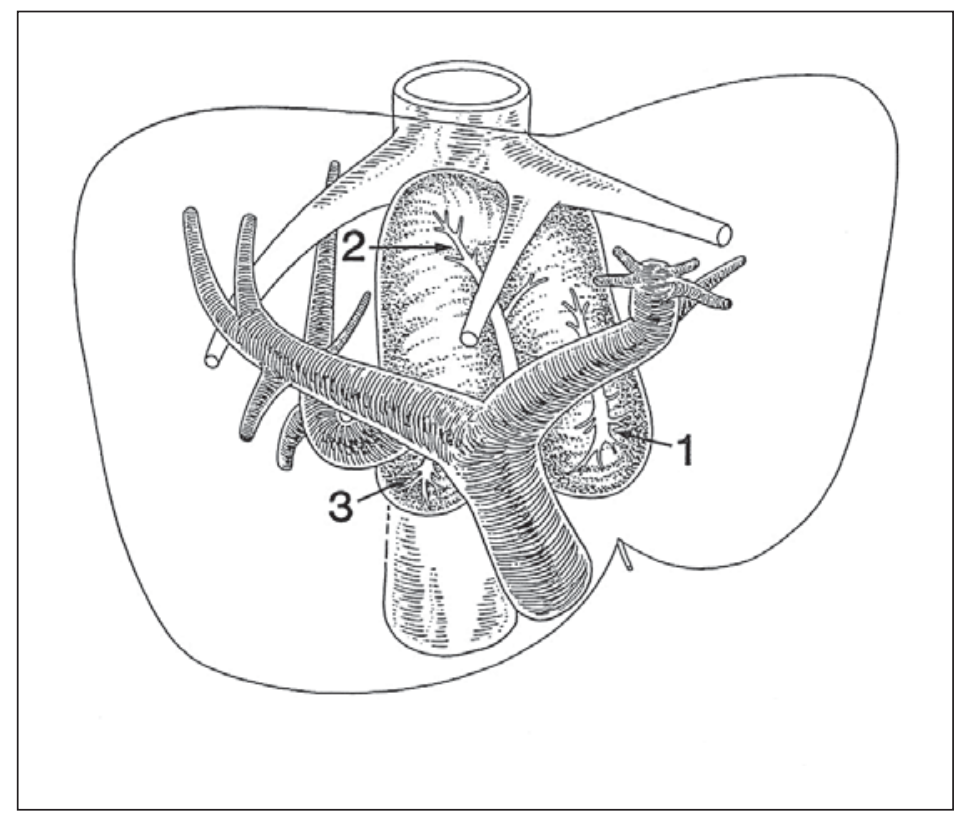

paracaval portion; and (3) caudate process portion. The study named the portal branches and biliary branches distributed in the respective caudate portions as follows: (1) Spiegel lobe branches; (2) paracaval branches; and (3) caudate process branches, to perform the investigations described below (Fig. 3, 4).

\section{Spiegel Lobe}

There was 1 portal venous branch distributed in the Spiegel lobe in 1 liver, 2 in 12 livers, 3 in 7 livers, and 4 in 3 livers. In 6 of these 23 livers, the portal venous branches were derived from the common trunk with paracaval portal venous branches described below. There was a mean of 2.52 branches that were considered to be portal venous branches in the Spiegel lobe.

The site of the portal venous branch ramifications that are distributed in the Spiegel lobe was then examined. The portal venous branches were most frequently ramified from the left portal vein (transverse portion) in 14 livers (60.9\%). They were ramified from both the transverse portion and the main portal trunk in 6 livers $(26.1 \%)$, from both the transverse portion and the right portal vein in 2 livers (8.7\%), and from the transverse portion, the main portal trunk and the right portal vein in 1 liver (4.3\%) (Table 2, left). In the portal vein bifurcation type, the Spiegel lobe portal venous branches were most frequently ramified from the transverse portion for $12(70.6 \%)$ of the 17 livers, whereas for the independent right posterior branch type, the Spiegel lobe branches were ramified from the main portal trunk after branching off the right posterior portal vein.

We then explored whether the biliary branches distributed in the Spiegel lobe might belong to the left or right biliary tract. Biliary branches only into the left biliary tract were observed in 11 livers (47.9\%), into the right and left biliary tracts in 8 livers (34.8\%), and into the right biliary tract only in 3 livers (13.0\%); the site was unclear in 1 liver (4.3\%) (Table 2, right).

There were 41 biliary branches confirmed in the Spiegel lobe in 22 livers, except in livers that were unassessable, and thus, there was an average of 1.86 biliary branches per liver. Of these 41 biliary branches, 16 (38.9\%) biliary branches drained into the left bile duct, 9 


\section{Liver Cancer}

Fig. 4. Configuration of the caudate lobe. Viewed from the ventral (a) and the caudal side (b).

\begin{tabular}{l|l}
\hline Liver Cancer 2017;6:161-170 \\
\hline DOI: 10.1159/000454682 & $\begin{array}{l}\text { @ 2016 S. Karger AG, Basel } \\
\text { www.karger.com/lic }\end{array}$ \\
\hline
\end{tabular}

Kumon: Anatomical Study of the Caudate Lobe with Special Reference to Portal Venous and Biliary Branches Using Corrosion Liver Casts and Clinical Application
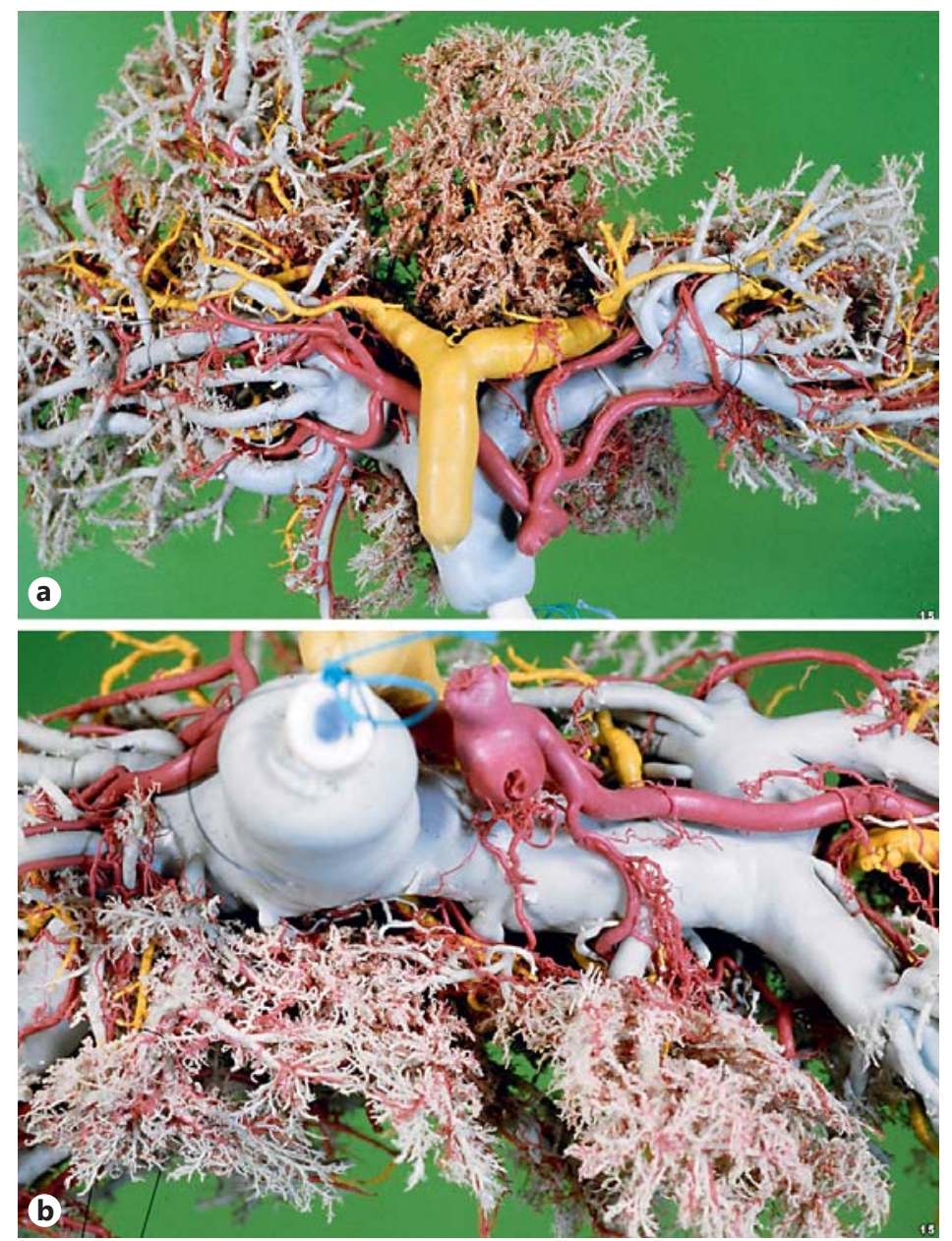

branches (22.0\%) drained into the bile duct in segment B2, 4 branches (9.8\%) drained into the bile duct in the left lateral section (B2 + B3), 8 branches (19.5\%) drained into the bile duct in the right posterior section, and 4 branches (9.8\%) drained into the right bile duct.

\section{Paracaval Portion}

Portal venous branches derived from the main portal trunk and cranial aspects of the right and left portal veins that connect primarily to the ventral side of the inferior vena cava were defined as paracaval branches and investigated. The portal venous branches that ramified from the contralateral side of the segment 5 portal vein root and distributed in the territory surrounded by the roots of the right and middle hepatic veins were defined as the portal branches of segment 8 (medial branches, $\mathrm{PV}^{8} \mathrm{c}$ ) [9], rather than as paracaval branches. Additionally, in the independent right posterior branch type, the ramification of the caudate portal venous branches is different from that of other types, and each branch designation is different. There were only 4 livers that showed this type. Therefore, the caudate branches in this type are further discussed below in the Discussion section.

The number of portal venous branches in the paracaval portion was examined in 19 livers after excluding the livers with the independent right posterior branch type. There was 1 portal venous branch in 15 (78.9\%) of the 19 livers, and 3, 2, 2, and 5 in the remaining 4 livers (livers No. 5, 7, 23, and 25, respectively). In liver No. 5, there were 3 portal venous 


\section{Liver Cancer}

Table 2. The site of bifurcation of the portal and biliary branches: the Spiegel lobe

\begin{tabular}{|c|c|c|}
\hline \multicolumn{3}{|l|}{ Liver Cancer 2017;6:161-170 } \\
\hline DOI: $10.1159 / 000454682$ & \multicolumn{2}{|c|}{$\begin{array}{l}\text { (C) } 2016 \text { S. Karger AG, Basel } \\
\text { www.karger.com/lic }\end{array}$} \\
\hline \multicolumn{3}{|c|}{$\begin{array}{l}\text { Kumon: Anatomical Study of the Caudate Lobe with Special Reference to Portal } \\
\text { Venous and Biliary Branches Using Corrosion Liver Casts and Clinical Applicatior }\end{array}$} \\
\hline Origin & Cases & $\%$ \\
\hline \multicolumn{3}{|l|}{ Portal branch } \\
\hline $\mathrm{L}$ & 14 & 60.9 \\
\hline $\mathrm{L}+\mathrm{M}$ & 4 & 17.4 \\
\hline $\mathrm{L}+\mathrm{M}^{\prime}$ & 2 & 8.7 \\
\hline $\mathrm{L}+\mathrm{R}$ & 2 & 8.7 \\
\hline $\mathrm{L}+\mathrm{M}+\mathrm{R}$ & 1 & 4.3 \\
\hline Total & 23 & 100 \\
\hline \multicolumn{3}{|l|}{ Biliary branch } \\
\hline Left ductal system & 11 & 47.9 \\
\hline Left and right ductal systems & 8 & 34.8 \\
\hline Right ductal system & 3 & 13.0 \\
\hline Unclear & 1 & 4.3 \\
\hline Total & 23 & 100 \\
\hline
\end{tabular}

L, left portal vein; M, main portal vein; M', main portal vein after ramified posterior branch; $\mathrm{R}$, right portal vein; $\mathrm{A}$, anterior portal branch; P, posterior portal branch.

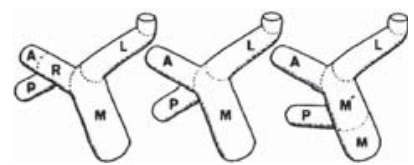

branches from the right portal vein. One branch mainly distributed in the Spiegel lobe, while the remaining branch supplied a limited territory in the paracaval portion. Small portal venous branches in livers No. 7 and 25 were excluded from the present investigation. In liver No. 23, an unexpectedly large portal venous branch extended dorsally from the right portal vein beyond the right hepatic vein, but it was determined that this was a right posterior portal vein.

After excluding aberrant branching and small branches, 19 portal venous branches were identified in 19 livers, and these were defined as paracaval venous branches and subjected to the following assessment. The roots of the paracaval branches were on the left portal vein (transverse portion) in 14 livers (73.7\%) and on the right portal vein in 5 livers $(26.3 \%$; Table 3). There were 6 livers in which the paracaval branches formed a common trunk with the Spiegel lobe branches.

To determine the extent of area supplied by the paracaval branch, these 19 livers were classified into the following 3 categories: (1) the paracaval branch reaching the liver surface beneath the diaphragm; (2) the paracaval branch distributed on the anterior aspect of the inferior vena cava and the dorsal aspect of the root of the major hepatic veins, but not reaching the liver surface; or (3) the paracaval branch supplying a small region. There were 10 livers $(52.6 \%)$ in category 1 , six livers $(31.6 \%)$ in category 2 , and 3 livers $(15.8 \%)$ in category 3 . In summary, the paracaval branch reached the liver surface beneath to the diaphragm in most of the livers.

We then assessed the biliary branches of the paracaval portion. First, we examined whether the biliary branches might belong to the left or right biliary tract. The paracaval biliary branches joined the left biliary tract in 10 (52.6\%) of 19 livers, and they joined the right biliary tract in 9 livers (47.4\%). In liver No. 6, two paracaval biliary branches coursed along the portal venous branch, ramifying from the transverse portion and draining into the 


\section{Liver Cancer}

Table 3. Comparison of the bifurcating site between the portal and biliary branches: the paracaval portion

\begin{tabular}{|c|c|c|c|}
\hline \multicolumn{4}{|c|}{ Liver Cancer 2017;6:161-170 } \\
\hline \multicolumn{2}{|l|}{ DOI: 10.1159/000454682 } & \multicolumn{2}{|c|}{$\begin{array}{l}\text { (C) } 2016 \text { S. Karger AG, Basel } \\
\text { www.karger.com/lic }\end{array}$} \\
\hline \multicolumn{4}{|c|}{$\begin{array}{l}\text { Kumon: Anatomical Study of the Caudate Lobe with Special Reference to Portal } \\
\text { Venous and Biliary Branches Using Corrosion Liver Casts and Clinical Application }\end{array}$} \\
\hline Biliary duct & $\begin{array}{l}\text { Right portal } \\
\text { vein }\end{array}$ & $\begin{array}{l}\text { Left portal } \\
\text { vein }\end{array}$ & $n$ \\
\hline Right ductal system & 4 & 5 & $9(47.4)$ \\
\hline Left ductal system & 1 & 9 & $10(52.6)$ \\
\hline Total & $5(26.3)$ & $14(73.7)$ & $19^{a}$ \\
\hline
\end{tabular}

Figures in parentheses indicate percentages. ${ }^{a}$ Excluded small and variational 8 branches.
Table 4. The site of bifurcation of the portal and biliary branches: the caudate process portion

\begin{tabular}{lcc}
\hline & Cases & $\%$ \\
\hline Portal branch, origin & & \\
$\quad$ Absent & 4 & 17.4 \\
$\quad$ Main portal vein & 5 & 21.7 \\
$\quad$ Right portal vein & 11 & 47.9 \\
$\quad$ Others & 3 & 13.0 \\
\hline Total & 23 & 100 \\
\hline Biliary branch, drainage site & & \\
$\quad$ Right hepatic duct & 3 & 13.0 \\
$\quad$ Posterior hepatic duct & 16 & 69.6 \\
$\quad$ Unknown & 4 & 17.4 \\
\hline Total & 23 & 100 \\
\hline
\end{tabular}

${ }^{a}$ Early ramificating type of the right posterior branch illustrated in Table 2.

right and left biliary tract, respectively. However, they were classified into the right biliary tract because the branch that drained into the right biliary tract was dominant (Table 3 ). Further investigation revealed that the paracaval biliary branches drained into the left bile duct in 9 livers (47.4\%) and into bile duct segment 2 in 1 liver (5.2\%). In addition, the paracaval biliary branches drained into the right posterior bile duct in 5 livers $(26.3 \%)$, into the right bile duct in 3 livers (15.8\%), and into the right anterior bile duct in 1 liver (5.2\%).

The relationship between the portal venous branches and the biliary branches of the paracaval portion is summarized in Table 3. The paracaval portal venous branches bifurcated frequently from the transverse portion $(73.7 \%)$, while the paracaval biliary branches drained into the right and left biliary tracts with similar frequency (right, 47.4\%; left, 52.6\%).

\section{Caudate Process Portion}

The caudate process portion is defined as the liver parenchyma surrounded by the main portal vein trunk and the right portal vein (ventral border), inferior vena cava (dorsal border), the Spiegel lobe (left border), and the right posterior section (right border). This region was considered to correspond to the caudate process that was described by Healey and Couinaud.

There was no portal venous branch in the caudate process portion in 4 livers, and there was 1 branch in 13 livers, 2 branches in 5 livers, and 3 branches in 1 liver. There was an average of 1.13 branches per liver. The portal venous branches in the Spiegel lobe partly distributed in the caudate process portion in 13 livers (56.5\%). In livers without caudate process branches, the portal venous branches from the Spiegel lobe or paracaval portion form the caudate process portion. The portal venous branches of the caudate process portion were 
Kumon: Anatomical Study of the Caudate Lobe with Special Reference to Portal

derived from the main portal trunk in 5 livers, from the right portal vein in 11 livers, and from the right posterior portal vein in 3 livers, which were associated with the independent right posterior branch type (Table 4, left).

The biliary branches of the caudate process portion joined the right biliary tract in 19 livers, excluding 4 livers where it was unclear. The right biliary branches joined the right posterior bile duct in 16 livers (84.2\%), and the right bile duct in 3 livers (15.8\%; Table 4, right).

\section{Discussion}

The caudate lobe is supplied by both the right and left portal veins and biliary tract. Therefore, it is considered important in hepatectomy and hilar cholangiocarcinoma surgery, although the parenchymal volume is small. Anatomical studies on the vascular systems of the caudate lobe have been reported $[4,5,10,11]$. However, a precise definition of the caudate lobe is unclear, and the clinical significance of this lobe has not been fully investigated.

Hjortsjö [10], Healey and Schroy [4], and Couinaud [5], the pioneers of the concept of hepatic segmentation, considered that the caudate lobe was composed of the caudate lobe and caudate process, although they differed somewhat in the terminology used. It is unclear from their descriptions, however, how much of the liver the caudate lobe included. For example, it is difficult to judge from Healey and Schroy's description and schematic illustration of the right portion of the caudate lobe, the exact extent of the liver that was included in this area. There is also no description of the positional relationship to the hepatic vein and inferior vena cava. Couinaud did not examine the border between the caudate lobe and the right liver (i.e., the right border and cranial extension of the caudate lobe) [Couinaud, pers. commun., 1984].

To clarify the extent of the caudate lobe, therefore, we classified the caudate lobe into the following three portions: (1) the Spiegel lobe; (2) the paracaval portion; and (3) the caudate process portion. We then used corrosion liver casts to investigate the portal venous branches and biliary branches that are distributed in these 3 portions.

The extent of the caudate lobe can be recognized based on this caudate lobe classification. The Spiegel lobe is situated on the left side of the inferior vena cava, dorsal to the lesser omentum and the Arantius duct. Thus, the Spiegel lobe can be recognized from the liver surface. The caudate process represents the portion that continues from the Spiegel lobe to the parenchyma of the right posterior section behind the main portal trunk and the right portal vein. There is no consensus on the extent of the caudate lobe. Based on the present investigation, we concluded that the ramification type of the left and right portal veins should be taken into consideration. Based on the corrosion liver casts, the portal venous branches ramifying dorsally from the main portal trunk and the right portal vein should be defined as the caudate process branches if the usual branching types (the bifurcation type and the trifurcation type) are present, while in the independent right posterior branch type [8], the caudate process branches should be defined differently. Thus, the border between the caudate process and the right liver eventually shifts to the right or left depending on the patient, which does not make sense clinically. However, it is reasonable to define the border between the caudate process and the right liver as described above, considering that there are noticeable interindividual differences in the size of the caudate process, the biliary branch distributed in the caudate process drains into the right biliary tract, the portal vein ramifies from the right portal vein or the main portal trunk, and the caudate process branch is easily identifiable intraoperatively and the resection of the caudate process portion is not technically demanding.

The paracaval portion represents the liver parenchyma that lies between the Spiegel lobe and the right liver on the ventral side of the inferior vena cava, and it is in contact ventrally 


\section{Liver Cancer}

\begin{tabular}{l|l}
\hline Liver Cancer 2017;6:161-170 \\
\hline DOI: 10.1159/000454682 & $\begin{array}{l}\text { @ 2016 S. Karger AG, Basel } \\
\text { www.karger.com/lic }\end{array}$ \\
\hline
\end{tabular}

Kumon: Anatomical Study of the Caudate Lobe with Special Reference to Portal

Venous and Biliary Branches Using Corrosion Liver Casts and Clinical Application

with the middle hepatic vein. The extent of this region to the right and the cranial side (diaphragmatic side) varies in individual patients, projecting to the right beyond the right margin of the inferior vena cava and reaching the liver surface directly beneath the cranial part of the diaphragm in patients with well-developed paracaval branches. In patients with small paracaval branches, however, the right border of the paracaval portion was nearly on the median line of the inferior vena cava because the right anterior superior medial portal vein $\left(\mathrm{PV}^{8} \mathrm{C}\right)[9]$ and/or the branch that ramified from the right posterior portal vein was large.

From the surgical point of view, it would be useful to classify the caudate lobe into 3 portions. Resection of the Spiegel lobe and caudate process is not technically demanding, but the portal veins and bile ducts in the paracaval portion have not been detailed in previously published textbooks and atlases. These details are not fully recognized by clinicians. Therefore, it is difficult to judge whether the paracaval portion identified here is included in the resected area or not, even though concomitant resection of the caudate lobe is described in the literature.

This study shows that the paracaval branch reaches the liver surface beneath the diaphragm in most livers. After conventional right or left hemihepatectomy, the paracaval portion remains unresected, and it is difficult to resect the caudate lobe completely. Thus, it is necessary to perform a right or left trisectionectomy to completely resect the caudate lobe including the paracaval portion. For hilar malignant neoplasms where the type of spread and the extent of invasion are the most important, the paracaval portion need not be totally resected when sufficient surgical margins can be secured. However, the paracaval biliary branches drain into the right and left biliary tracts at the same frequency, and they may occasionally be confluent at a site close to the bifurcation of the right and left hepatic ducts. Therefore, it is important to determine the extent of surgical resection by fully taking into account the extent of invasion to the biliary branches, including the branches of the paracaval portion, while performing surgery for hilar malignant neoplasms.

\section{Conclusion}

To clarify the definition and extent of the caudate lobe, in the study, we assessed the portal venous branches and biliary branches using corrosion liver casts to classify the caudate lobe into the following areas: (1) the Spiegel lobe; (2) the paracaval portion; and (3) the caudate process portion.

Our findings showed that the paracaval portion of the liver is most important for clarifying the extent of the caudate lobe. Although the clinical impact of complete resection of the paracaval portion branches seems limited, these branches may supply a large area in some patients. Therefore, it is important for surgeons to fully recognize and pay attention to the paracaval portion.

\section{Acknowledgements}

The author wishes to extend his heartfelt gratitude to Prof. Takuro Ogata for kind guidance and careful review of the manuscript. The author is also indebted to Doctors at the Department of Pathology, National Cancer Center Research Institute, National Hospital Organization Matsudo Hospital, and the Departments of Legal Medicine and Pathology, Kochi Medical School, for their collaboration in this study. Thanks are also extended to Dr. Hiroshi Hasegawa, Department Chief, National Cancer Center, and Dr. Yoshiyuki Shimamura, Chief of the Department of Surgery, National Hospital Organization Matsudo Hospital, who provided valuable advice, especially from the clinical viewpoint. 


\section{Acknowledgements (Translation Version)}

The author sincerely thanks Dr. Norihiro Kokudo, Dr. Yoshihiro Sakamoto, Dr. Yoshikuni Kawaguchi, and Dr. Harufumi Maki for initiating the secondary publication project and their extensive work on translating the original article, which was published in 1985.

\section{Disclosure Statement}

The author declares no conflicts of interest.

\section{References}

1 Hasegawa H, Yamazaki S, Makuuchi M, et al: An expedient for en bloc subtotal excision of the caudate lobe for treatment of hepatocellular carcinoma (in Japanese). Jpn J Gastroenterol Surg 1982;15:925.

2 Kawarada Y, Suzuki H, Mizumoto R: Anatomical peculiarities of portal vasculatures and surgical treatment of hilar cholangiocarcinoma (in Japanese). Jpn J Gastroenterol Surg 1984;17:233.

3 Iwase M, Hasegawa H, Kamiya J, et al: A case of primary biliary cystadenocarcinoma of the right caudate lobe treated by left paramedian sectoriectomy with caudate lobe resection (in Japanese). Jpn J Gastroenterol Surg 1984;17:488.

4 Healey JE, Schroy PC: Anatomy of the biliary ducts within the human liver. Arch Surg 1953;66:599-616.

5 Couinaud C: Le foie. Etudes anatomiques et chirugicales. Paris, Masson \& Cie, 1957.

6 Kumon M, Takahashi A, Shimamura Y, et al: Corrosion liver casts with a new injection material - how to make flexible liver casts (in Japanese). Kanzo (Acta Hepatol Jpn) 1983;29:1008-1011.

7 Kumon M: Corrosion liver casts and their clinical application - how to prepare corrosion liver casts with silicone rubber (in Japanese). J Okayama Med Assoc 1985;97:11.

8 Kinoshita H, Yamazaki O, Inoue T: Analysis of intrahepatic portal venous branches and diagnosis of portal vein tumor thrombosis using PTP (in Japanese). Jpn J Surg Soc 83rd Gen Conf Issue 1983;306.

9 Kumon M, Araki K, Ogata T, et al: Corrosion liver casts and their clinical application - discussion on ramification type of right anterior portal venous branches and anatomical resection of hepatic segment (in Japanese). Kantansui 1984;8:265-270.

10 Hjortsjo CH: The topography of the intrahepatic duct system. Acta Anat 1951;11:599-615.

11 Suzuki H: Correlation and abnormalities of Glissonian hepatic vessels in hepatic porta regions - from the viewpoint of biliary tract surgery (in Japanese). Arch Jpn Chir 1982;51:713-731. 